\title{
Postextubation respiratory events in patients admitted to the intensive care unit: a prospective pilot study using overnight respiratory polygraphy
}

\author{
Ye Jin Lee', Jinwoo Lee ${ }^{2,3}$, Sang-Min Lee ${ }^{2,3}$, Jaeyoung Cho $^{2}$ \\ ${ }^{1}$ Division of Pulmonary, Allergy and Critical Care Medicine, Department of Internal Medicine, Kangdong Sacred Heart Hospital, Seoul,; Division of Pulmonary \\ and Critical Care Medicine, Department of Internal Medicine, Seoul National University Hospital, Seoul; ${ }^{3}$ Department of Internal Medicine, Seoul National \\ University College of Medicine, Seoul, Korea
}

Background: Before the main trial in which respiratory polygraphy will be used to evaluate postextubation sleep apnea in critically ill patients, we performed a prospective pilot study to ensure that any issues with the conduct of the trial would be identified.

Methods: In the present study, 13 adult patients who had received mechanical ventilation for $\geq 24$ hours were prospectively recruited. Among the patients, 10 successfully completed respiratory polygraphy on the first or second night after extubation. Data regarding the types and doses of corticosteroids, analgesics, sedatives, and muscle relaxants as well as the methods of oxygen delivery were recorded.

Results: During the night of respiratory polygraphy, all 10 patients received supplemental oxygen (low-flow oxygen, $n=5$; high-flow oxygen, $n=5$ ), and seven patients received intravenous corticosteroids. Three of the 10 patients had a respiratory event index (REI) $\geq 5 / \mathrm{hr}$. All respiratory events were obstructive episodes. None of the patients receiving high-flow oxygen therapy had an REl $\geq 5 / \mathrm{hr}$. Two of the seven patients who received corticosteroids and one of the other three patients who did not receive this medication had an REI $\geq 5 / \mathrm{hr}$. Although low- or high-flow oxygen therapy was provided, all patients had episodes of oxygen saturation $\left(\mathrm{SpO}_{2}\right)<90 \%$. Two of the three patients with an $\mathrm{REI} \geq 5 / \mathrm{hr}$ underwent in-laboratory polysomnography. The patients' Apnea-Hypopnea Index and REI obtained via polysomnography and respiratory polygraphy, respectively, were similar.

Conclusions: In a future trial to evaluate postextubation sleep apnea in critically ill patients, pre-stratification based on the use of corticosteroids and high-flow oxygen therapy should be considered.

Key Words: airway extubation; intensive care unit; pilot projects; sleep apnea

\section{INTRODUCTION}

Obstructive sleep apnea (OSA) is prevalent and present in 9\%-38\% of the general population [1]. OSA is frequently comorbid with cardiovascular, cerebrovascular, and metabolic diseases [2], and is associated with increased health care costs [3] and mortality rates [4]. According to retrospective studies conducted among Caucasian populations, approximately $10 \%$ of the patients admitted to the intensive care unit (ICU) had previously been diagnosed with OSA

\section{Original Article}

Received: July 1, 2020

Revised: August17, 2020

Accepted: August 25, 2020

Corresponding author

Jaeyoung Cho

Division of Pulmonary and Critical Care Medicine, Department of Internal Medicine, Seoul National University Hospital, 101 Daehak-ro, Jongno-gu, Seoul 03080, Korea Tel: +82-2-2072-2503

Fax: +82-2-762-9662

E-mail: apricot6@snu.ac.kr

Copyright @ 2020 The Korean Society of Critical Care Medicine

This is an Open Access article distributed under the terms of Creative Attributions Non-Commercial License (https:// creativecommons.org/li-censes/by-nc/4.0/) which permits unrestricted noncommercial use, distribution, and reproduction in any medium, provided the original work is properly cited. 
$[5,6]$. In another prospective study, all 16 patients admitted to the ICU for acute hypercapnic respiratory failure had sleep apnea when polysomnography (PSG) was conducted after their ICU discharge [7]. However, until recently, the occurrence of postextubation sleep apnea was not investigated in patients admitted to the ICU. In a recent study in which postextubation sleep apnea was investigated in Caucasian patients admitted to the surgical ICU, $70 \%$ of the patients had sleep apnea [8]. In extubated patients, upper airway obstruction may occur due to mechanical tissue injury caused by endotracheal intubation, inflammation in the upper airway $[9,10]$, presence of secretions, and rostral fluid shift [11]. In addition, although the use of opioids during mechanical ventilation improves a patient's tolerance to mechanical ventilation, the risk of respiratory depression is increased [12].

Overnight PSG is the gold standard for the diagnosis of OSA. However, PSG is expensive, time-consuming, and labor-intensive [13]. Furthermore, PSG may not be suitable for critically ill patients because of the potential risks associated with out-of-ICU transportation. Portable respiratory polygraphy is an accepted alternative for OSA diagnosis in uncomplicated patients with an increased risk of moderate to severe OSA. Before the main trial with respiratory polygraphy for the evaluation of postextubation sleep apnea in critically ill patients in South Korea where relevant data are scarce, we performed a prospective pilot study to ensure that any problems with the conduct of the trial would be identified.

\section{MATERIALS AND METHODS}

\section{Study Participants and Design}

This study was approved by the Institutional Review Board of Seoul National University Hospital (IRB No. H-1802-051-921). All participants provided written informed consent and the study was conducted in accordance with the tenets of the declaration of Helsinki 2013.

In this prospective study, adult patients who had received mechanical ventilation for $\geq 24$ hours and were extubated in the medical ICU at Seoul National University Hospital from August 2018 to May 2019 were recruited. Unconscious patients and those with tracheostomy or immediate need for non-invasive ventilation after extubation were excluded. A type 3 sleep study using respiratory polygraphy (Embla-Embletta; Natus, Pleasanton, CA, USA) was conducted from 10 $\mathrm{PM}$ of the first or second night after extubation to $7 \mathrm{AM}$ of the next day. The respiratory polygraphy test included the measurement of airflow, oxygen saturation $\left(\mathrm{SpO}_{2}\right)$, and respiratory

\section{KEY MESSAGES}

- Our pilot study indicates that pre-stratification based on the use of corticosteroids and high-flow oxygen therapy should be applied in a future trial to evaluate postextubation sleep apnea in critically ill patients.

- In addition, the use of respiratory polygraphy in critically ill patients should be validated against polysomnography.

effort using an oronasal thermal sensor and nasal pressure transducer, pulse oximeter, and dual thoracoabdominal respiratory inductance plethysmography belt, respectively. In the setting of a single-bed room in our medical ICU, a physician connected the respiratory polygraphy device to the patient; however, the overnight recording was unattended.

\section{Measurements}

The following data were collected: age, sex, body mass index (BMI), and neck circumference; cardinal symptoms of sleep apnea including excessive daytime sleepiness, nonrestorative sleep, fatigue, insomnia, snoring, and witnessed apnea; snoring, tiredness, observed apnea, high blood pressure, BMI, age, neck circumference, gender (STOP-Bang) score; comorbidities and severity scores obtained from the Acute Physiology and Chronic Health Evaluation II (APACHE II), Simplified Acute Physiology Score (SAPS), and Sequential Organ Failure Assessment (SOFA) upon ICU admission; reason for and duration of mechanical ventilation, type and dose of corticosteroids, analgesics, sedatives, and muscle relaxants administered 48 hours prior to extubation, and methods of oxygen delivery during the night of respiratory polygraphy.

Apnea was defined as $\geq 90 \%$ decrease in the peak signal excursion from the pre-event baseline using an oronasal thermal sensor for $\geq 10$ seconds. If the signal of the oronasal thermal sensor was not reliable, the nasal pressure sensor was used as an alternative. Hypopnea was defined as $\geq 30 \%$ decrease in peak signal excursion from the pre-event baseline using a nasal pressure sensor for $\geq 10$ seconds and as $\geq 3 \%$ oxygen desaturation from the pre-event baseline [14]. The monitoring time was calculated by subtracting the upright time from the total recording time. The respiratory event index (REI) was calculated as the number of apneas plus hypopneas divided by the monitoring time. A patient with REI $\geq 5 / \mathrm{hr}$ was diagnosed as having postextubation respiratory events. The oxygen desaturation index (ODI) was defined as episodes of $\geq 3 \%$ oxygen desaturations per hour during the monitoring time. 


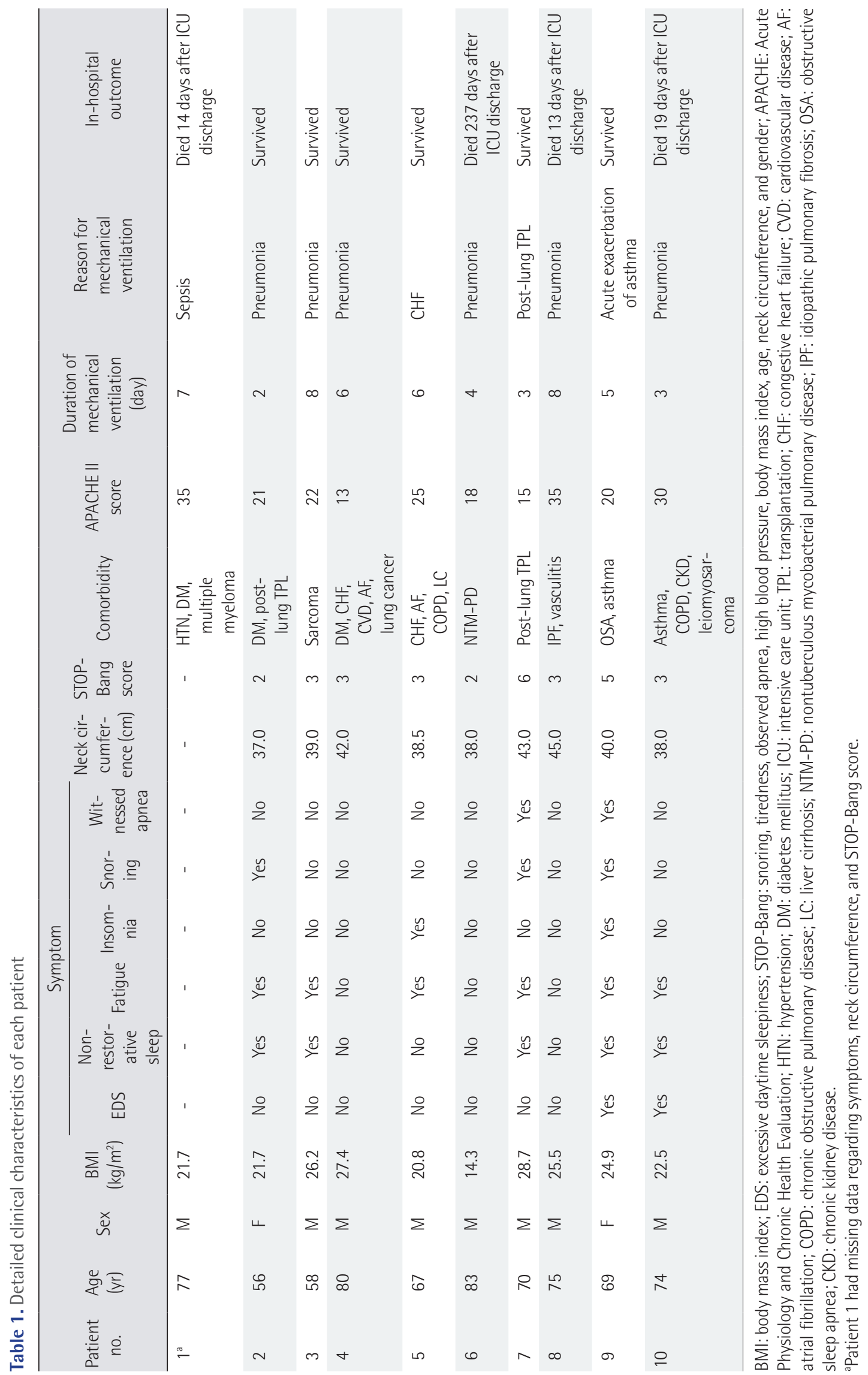




\section{RESULTS}

Among the 65 patients who received mechanical ventilation for $\geq 24$ hours and were extubated during the study period, 13 were enrolled in the present study. Regarding demographic characteristics, severity scores, reason and duration of mechanical ventilation, and length of ICU stay, differences between enrolled and non-enrolled patients were not observed
(Supplementary Table 1). Among the 13 patients, one was reintubated due to acute deterioration before applying respiratory polygraphy. The other two patients were excluded from the analysis due to a monitoring time $<4$ hours, which was attributed to the detachment of both oronasal thermal and nasal pressure sensors. The clinical characteristics of 10 patients (eight males and two females) are shown in Tables 1 and 2. The median age and BMI of the patients were 72 years and

Table 2. Clinical characteristics based on the presence of postextubation respiratory events

\begin{tabular}{|c|c|c|c|}
\hline Variable & $\begin{array}{l}\text { All patients } \\
\quad(n=10)\end{array}$ & $\begin{array}{l}\text { Patient with an } \\
\mathrm{REI}<5 / \mathrm{hr}(\mathrm{n}=7)\end{array}$ & $\begin{array}{l}\text { Patient with an } \\
\mathrm{REI} \geq 5 / \mathrm{hr}(\mathrm{n}=3)\end{array}$ \\
\hline Age (yr) & $72(67-77)$ & $74(67-77)$ & $69(56-83)$ \\
\hline Male sex & $8(80)$ & $7(100)$ & $1(33)$ \\
\hline BMI $\left(\mathrm{kg} / \mathrm{m}^{2}\right)$ & $23.7(21.7-26.2)$ & $25.5(21.7-27.4)$ & $21.7(14.3-24.9)$ \\
\hline Neck circumference $(\mathrm{cm})^{\mathrm{a}}$ & $39(38-42)$ & $41(39-43)$ & $38(37-40)$ \\
\hline STOP-Bang score $\geq 3^{\text {a }}$ & $7(70)$ & $6(86)$ & $1(33)$ \\
\hline Charlson comorbidity index & $5(3-8)$ & $6(5-8)$ & $2(0-3)$ \\
\hline Hypertension & $1(10)$ & $1(14)$ & 0 \\
\hline Diabetes & $3(30)$ & $2(29)$ & $1(33)$ \\
\hline Congestive heart failure & $2(20)$ & $2(29)$ & 0 \\
\hline COPD & $2(20)$ & $2(29)$ & 0 \\
\hline APACHE II score & $22(18-30)$ & $25(15-35)$ & $20(18-21)$ \\
\hline SOFA score & $6(5-10)$ & $9(4-10)$ & $5(5-7)$ \\
\hline SAPS II & $48(32-66)$ & $54(32-68)$ & $46(30-50)$ \\
\hline Failure during the first intubation attempt & $4(40)$ & $3(43)$ & $1(33)$ \\
\hline Internal diameter of the endotracheal tubes (mm) & $7.5(7.5-7.5)$ & $7.5(7.5-7.5)$ & $7.5(7.0-7.5)$ \\
\hline Duration of mechanical ventilation (day) & $6(3-7)$ & $6(3-8)$ & $4(2-5)$ \\
\hline \multicolumn{4}{|l|}{ Reason for mechanical ventilation } \\
\hline Pneumonia & $6(60)$ & $4(57)$ & $2(67)$ \\
\hline Acute exacerbation of asthma & $1(10)$ & 0 & $1(33)$ \\
\hline Heart failure & $1(10)$ & $1(14)$ & 0 \\
\hline Sepsis & $1(10)$ & $1(14)$ & 0 \\
\hline Post-lung transplantation & $1(10)$ & $1(14)$ & 0 \\
\hline \multicolumn{4}{|c|}{ Total drug equivalent dose administered 48 hours prior to extubation } \\
\hline Remifentanyl (mg) & $7.4(4.2-10.6)$ & $9.6(4.2-22.1)$ & $4.8(1.8-9.6)$ \\
\hline Propofol (mg) & $0(0-1,344)$ & $0(0-1,728)$ & $0(0-1,344)$ \\
\hline Dexmedetomidine (mg) & $1.1(0.04-3.0)$ & $0.8(0.04-3.6)$ & $1.5(0-3.0)$ \\
\hline Methylprednisolone (mg) & $78(0-120)$ & $60(0-160)$ & $100(0-120)$ \\
\hline \multicolumn{4}{|c|}{ Method of oxygen delivery during the night of respiratory polygraphy } \\
\hline Low-flow oxygen therapy via nasal prong & $5(50)$ & $2(29)$ & $3(100)$ \\
\hline High-flow nasal cannula & $5(50)$ & $5(71)$ & 0 \\
\hline $\mathrm{FiO}_{2}$ & $0.4(0.3-0.5)$ & $0.4(0.4-0.6)$ & $0.3(0.3-0.4)$ \\
\hline Flow (L/min) & $23(2-60)$ & $40(4-60)$ & $2(2-6)$ \\
\hline
\end{tabular}

Values are presented as median (interquartile range) or number (\%).

REI: respiratory event index; BMI: body mass index; STOP-Bang: snoring, tiredness, observed apnea, high blood pressure, body mass index, age, neck circumference, and gender; COPD: chronic obstructive pulmonary disease; APACHE: Acute Physiology and Chronic Health Evaluation; SOFA: Sequential Organ Failure Assessment; SAPS: Simplified Acute Physiology Score; $\mathrm{FiO}_{2}$ : fraction of inspired oxygen.

apatient 1 had missing data regarding neck circumference and STOP-Bang score. 
$23.7 \mathrm{~kg} / \mathrm{m}^{2}$, respectively. The median neck circumference was $39 \mathrm{~cm}$, and seven of nine patients had a STOP-Bang score $\geq 3$. All patients presented with at least one chronic disease and the median APACHE II score was 22. The median duration of mechanical ventilation was 6 days. Muscle relaxants or midazolam were not administered 48 hours prior to extubation. Propofol and dexmedetomidine were administered 48 hours prior to extubation to three and eight patients, respectively. Remifentanil was used as an analgesic in all patients. Seven patients received systemic corticosteroids. The drug dose for each participant is listed in Table 3. During the night of respiratory polygraphy, all patients received supplemental oxygen. Specifically, five patients received high-flow nasal cannula (HFNC) therapy.

Table 3 shows the findings of respiratory polygraphy for each patient. All respiratory events were obstructive episodes. Three patients had REI $\geq 5 / \mathrm{hr}$. None of the patients receiving HFNC therapy had REI $\geq 5 / \mathrm{hr}$ (Figure 1A). Furthermore, two (29\%) of the seven patients who received corticosteroids and one (33\%) of the other three who did not receive the drug had $\mathrm{REI} \geq 5 / \mathrm{hr}$ (Figure 1B). All patients had episodes of $\mathrm{SpO}_{2}<90 \%$ although low- or high-flow oxygen therapy was provided, and one patient (patient 10) receiving HFNC therapy with a flow rate of $40 \mathrm{~L} / \mathrm{min}$ and fraction of inspired oxygen $\left(\mathrm{FiO}_{2}\right)$ of 0.6 had $\mathrm{SpO}_{2}<90 \%$ during $20 \%$ of the monitoring time (Table 3). The median lowest $\mathrm{SpO}_{2}$ was $86 \%$ (82\%-87\%) and the ODI varied from $0.1-14.7 / \mathrm{hr}$.

Two of the three patients with REI $\geq 5 / \mathrm{hr}$ underwent type 1 attended in-laboratory PSG. At the time of PSG, the patients were medically stable after ICU discharge and did not require oxygen supplementation. Patient 2 was a 56-year-old female with diabetes mellitus who had received a lung transplantation due to connective tissue disease-associated interstitial lung disease (Sjogren's syndrome) approximately 1 year ago. She was admitted to our medical ICU due to aspiration pneumonia with type 1 respiratory failure. Respiratory polygraphy was performed on the second night after extubation. She was treated with intravenous corticosteroids and oxygen supplementation via nasal prong during the type 3 sleep study. Her REI was $7.5 / \mathrm{hr}$ and the lowest $\mathrm{SpO}_{2}$ was $74 \%$. Furthermore, during the 537-minute monitoring period, the time spent with $\mathrm{SpO}_{2}<90 \%$ was 5 minutes and the ODI was $8.1 / \mathrm{hr}$. Twelve days after ICU discharge, the patient underwent PSG and her Apnea-Hypopnea Index (AHI) was 7.6/hr. Patient 9 was 69 years old and had asthma and a history of pulmonary tuberculosis. She had used the continuous positive airway pressure machine after the diagnosis of OSA 8 years previously, howev-

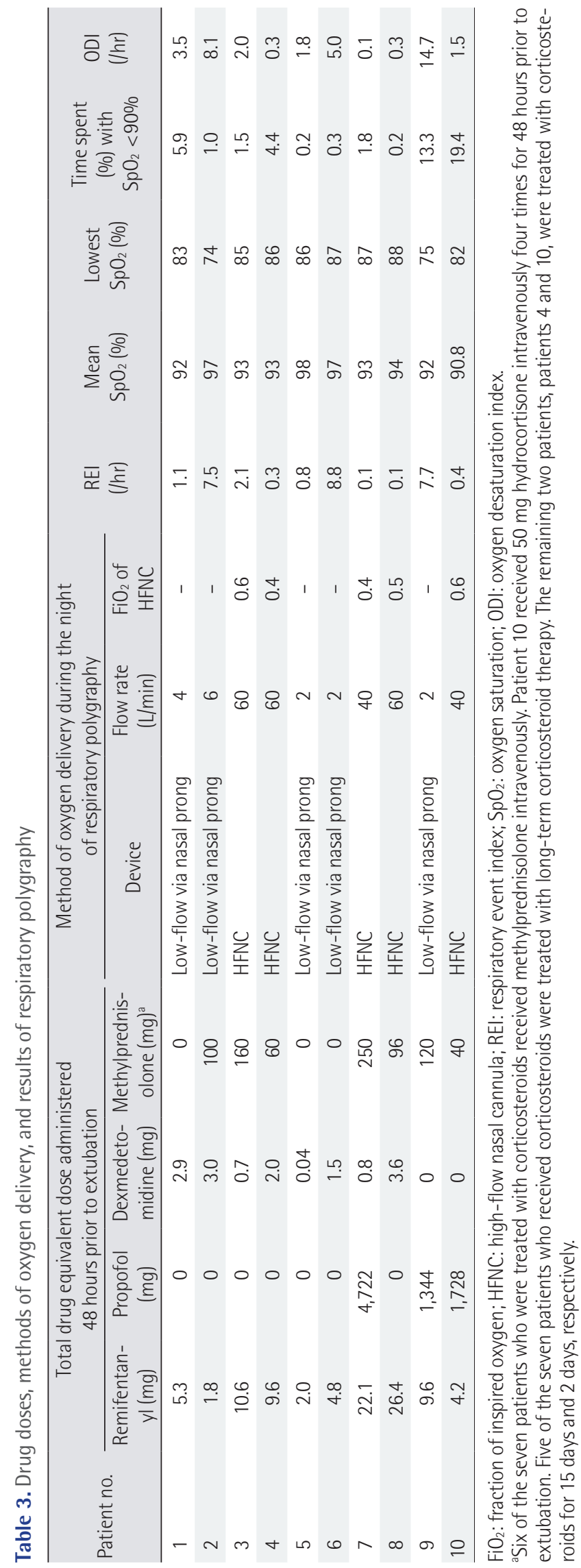



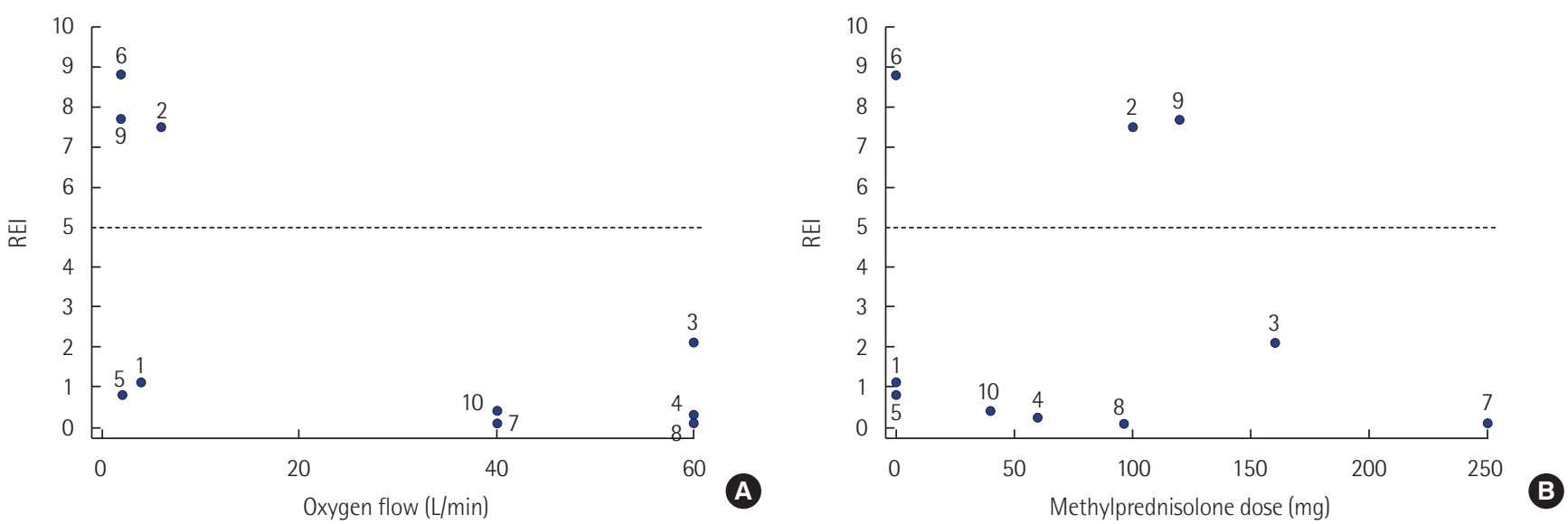

Figure 1. Scatter plots of the postextubation respiratory event index (REI) and (A) the flow rate of oxygen during the night of respiratory polygraphy, and (B) the equivalent dose of methylprednisolone administered 48 hours prior to extubation.

er, the use of the device was discontinued due to intolerance. The patient was then admitted to our medical ICU and treated with mechanical ventilation due to type 2 respiratory failure caused by an acute exacerbation of asthma. Respiratory polygraphy was conducted on the first night after extubation. She was treated with intravenous steroid and oxygen supplementation via nasal prong during the study. Her REI was 7.7/hr and the lowest $\mathrm{SpO}_{2}$ was $75 \%$. During the 536-minute monitoring period, the time spent with $\mathrm{SpO}_{2}<90 \%$ was $54.8 \mathrm{~min}$ utes and the ODI was $14.7 / \mathrm{hr}$. When the patient underwent PSG 9 days after ICU discharge, her AHI was 10.7/hr.

\section{DISCUSSION}

In this prospective pilot study, three of 10 patients admitted to the medical ICU had postextubation respiratory events on the first or second night after extubation from mechanical ventilation. Furthermore, the patients experienced frequent oxygen desaturation during those nights. In previous studies conducted in the ICU, the prevalence of postextubation sleep apnea in Caucasians was reportedly approximately $70 \%[8,15,16]$. The low rate of postextubation respiratory events in the current study could be explained in several ways. First, different types of the sleep study (type 3 vs. type 1) and study populations (medical vs. surgical ICU patients, Asians vs. Caucasians) could produce different results. Respiratory polygraphy may result in an underestimation of the severity of sleep apnea because the estimation of REI using this device is based on the monitoring time rather than total sleep time. Furthermore, PSG allows for the scoring of hypopnea based on $\mathrm{SpO}_{2}$ as well as arousal $[17,18]$.

Second, the seven patients (70\%) in the present study received systemic corticosteroids, which were administered throughout the ICU stay including the pre-extubation and postextubation periods. The use of corticosteroids can reduce upper airway edema caused by mucosal injury and can prevent airway obstruction after extubation $[19,20]$. Although the seven patients received corticosteroids for reasons other than laryngospasm or laryngeal edema (e.g., immune modulator), the use of corticosteroids before extubation might have an effect on upper airway edema in the present study.

Third, the relatively low rate of postextubation respiratory events could be explained by the extensive use of HFNC. In the present study, half of the patients received HFNC therapy, and all patients receiving HFNC had $\mathrm{REI}<5 / \mathrm{hr}$. In several studies, HFNC reduced arousals and AHI, and improved oxygenation in both children and adults [21-25]. The mechanism of action is apparently an increase in end-expiratory pharyngeal pressure which reduced upper airway obstruction [22,26].

In the present study, the patients with $\mathrm{REI}<5 / \mathrm{hr}$ had a high STOP-Bang score and were more likely to be male and older and have higher BMI and neck circumference than patients with REI $\geq 5 / h$. Furthermore, the patients with REI $<5 /$ hr appeared to be more severely ill and have more comorbidities and longer duration of mechanical ventilation. The frequent use of HFNC in more severely ill patients might lead to a low rate of postextubation respiratory events.

The present study had several limitations. First, the pilot study was limited by a small sample size. Second, although a cuff leak test before extubation was routinely performed, an evaluation of the upper airway after extubation was not consistently implemented. Third, prolonged wake after sleep onset, as a reflection of sleep fragmentation, is commonly observed in patients admitted to the ICU [27]. Because sleep architecture was not evaluated, and total sleep time could not 
be accurately assessed, the occurrence of postextubation sleep apnea may have been underestimated $[17,18]$. Based on this limitation, the lights were turned off and noise and patientcare activities (e.g., nursing rounds and blood tests) reduced in the setting of a single-bed room to promote sleep at night. Finally, as a diagnostic tool in critically ill patients, respiratory polygraphy has not been validated but is not inferior to PSG in diagnosing uncomplicated OSA in the general population [17, 28]. Nonetheless, the REI and AHI obtained using respiratory polygraphy and PSG, respectively, were similar in the two patients in our study.

To evaluate postextubation sleep apnea with respiratory polygraphy in critically ill patients, a future main trial with adequate power should be conducted. The present pilot study results indicate pre-stratification based on the use of corticosteroids and HFNC should be applied. In addition, the use of respiratory polygraphy in critically ill patients should be validated against PSG.

\section{CONFLICT OF INTEREST}

No potential conflict of interest relevant to this article was reported.

\section{ORCID}

Ye Jin Lee https://orcid.org/0000-0002-7290-0265

Jinwoo Lee https://orcid.org/0000-0003-0958-106X

Sang-Min Lee https://orcid.org/0000-0002-1388-9318

Jaeyoung Cho https://orcid.org/0000-0002-6537-8843

\section{AUTHOR CONTRIBUTIONS}

Conceptualization: JL, JC. Data curation: YJL. Formal analysis: YJL. Methodology: YJL, SML, JL. Project administration: SML, JL. Visualization: YJL. Writing-original draft: YJL. Writing-review and editing: JC, SML, JL.

\section{SUPPLEMENTARY MATERIALS}

Supplementary materials can be found at https://doi.org/10. 4266/acc.2020.00479.

\section{REFERENCES}

1. Senaratna CV, Perret JL, Lodge CJ, Lowe AJ, Campbell BE, Matheson MC, et al. Prevalence of obstructive sleep apnea in the general population: a systematic review. Sleep Med Rev 2017;34:70-81.

2. Kryger MH, Roth T, Dement WC. Principles and practice of sleep medicine. Philadelphia: Elsevier; 2016.

3. Leger D, Bayon V, Laaban JP, Philip P. Impact of sleep apnea on economics. Sleep Med Rev 2012;16:455-62.

4. Young T, Finn L, Peppard PE, Szklo-Coxe M, Austin D, Nieto FJ, et al. Sleep disordered breathing and mortality: eighteenyear follow-up of the Wisconsin sleep cohort. Sleep 2008;31: 1071-8.

5. Jean RE, Gibson CD, Jean RA, Ochieng P. Obstructive sleep apnea and acute respiratory failure: an analysis of mortality risk in patients with pneumonia requiring invasive mechanical ventilation. J Crit Care 2015;30:778-83.

6. Bolona E, Hahn PY, Afessa B. Intensive care unit and hospital mortality in patients with obstructive sleep apnea. J Crit Care 2015;30:178-80.

7. Thille AW, Córdoba-Izquierdo A, Maitre B, Boyer L, Brochard L, Drouot X. High prevalence of sleep apnea syndrome in patients admitted to ICU for acute hypercapnic respiratory failure: a preliminary study. Intensive Care Med 2018;44:267-9.

8. Timm FP, Zaremba S, Grabitz SD, Farhan HN, Zaremba S, Siliski E, et al. Effects of opioids given to facilitate mechanical ventilation on sleep apnea after extubation in the intensive care unit. Sleep 2018;41.

9. Bergeron C, Kimoff J, Hamid Q. Obstructive sleep apnea syndrome and inflammation. J Allergy Clin Immunol 2005;116: 1393-6.

10. Vicente E, Marin JM, Carrizo SJ, Osuna CS, González R, MarinOto M, et al. Upper airway and systemic inflammation in obstructive sleep apnoea. Eur Respir J 2016;48:1108-17.

11. Ogna A, Forni Ogna V, Mihalache A, Pruijm M, Halabi G, Phan $\mathrm{O}$, et al. Obstructive sleep apnea severity and overnight body fluid shift before and after hemodialysis. Clin J Am Soc Nephrol 2015;10:1002-10.

12. Montandon G, Qin W, Liu H, Ren J, Greer JJ, Horner RL. PreBotzinger complex neurokinin-1 receptor-expressing neurons mediate opioid-induced respiratory depression. J Neurosci 2011;31:1292-301.

13. Jordan AS, McSharry DG, Malhotra A. Adult obstructive sleep apnoea. Lancet 2014;383:736-47.

14. Berry RB, Brooks R, Gamaldo C, Harding SM, Lloyd RM, Quan SF, et al. AASM scoring manual updates for 2017 (version 2.4). J Clin Sleep Med 2017;13:665-6.

15. Chishti A, Batchelor AM, Bullock RE, Fulton B, Gascoigne AD, Baudouin SV. Sleep-related breathing disorders following discharge from intensive care. Intensive Care Med 2000;26:426- 
33.

16. Chung F, Liao P, Elsaid H, Shapiro CM, Kang W. Factors associated with postoperative exacerbation of sleep-disordered breathing. Anesthesiology 2014;120:299-311.

17. Tan HL, Gozal D, Ramirez HM, Bandla HP, Kheirandish-Gozal L. Overnight polysomnography versus respiratory polygraphy in the diagnosis of pediatric obstructive sleep apnea. Sleep 2014;37:255-60.

18. Bianchi MT, Goparaju B. Potential underestimation of sleep apnea severity by at-home kits: rescoring in-laboratory polysomnography without sleep staging. J Clin Sleep Med 2017;13: 551-5.

19. Kuriyama A, Umakoshi N, Sun R. Prophylactic corticosteroids for prevention of postextubation stridor and reintubation in adults: a systematic review and meta-analysis. Chest 2017;151: 1002-10.

20. Prajapat B, Sandhya AS, Chaudhry D, Esquinas AM. Opioids in intensive care unit (ICU): causal agent for sleep apnea, unmasking the undiagnosed sleep apnea or both in the ICU. Sleep 2018;41:zsy081.

21. McGinley B, Halbower A, Schwartz AR, Smith PL, Patil SP, Schneider $\mathrm{H}$. Effect of a high-flow open nasal cannula system on obstructive sleep apnea in children. Pediatrics 2009;124:17988.
22. McGinley BM, Patil SP, Kirkness JP, Smith PL, Schwartz AR, Schneider H. A nasal cannula can be used to treat obstructive sleep apnea. Am J Respir Crit Care Med 2007;176:194-200.

23. Joseph L, Goldberg S, Shitrit M, Picard E. High-flow nasal cannula therapy for obstructive sleep apnea in children. J Clin Sleep Med 2015;11:1007-10.

24. Hawkins S, Huston S, Campbell K, Halbower A. High-flow, heated, humidified air via nasal cannula treats CPAP-intolerant children with obstructive sleep apnea. J Clin Sleep Med 2017;13:981-9.

25. Amaddeo A, Khirani S, Frapin A, Teng T, Griffon L, Fauroux B. High-flow nasal cannula for children not compliant with continuous positive airway pressure. Sleep Med 2019;63:24-8.

26. Nishimura M. High-flow nasal cannula oxygen therapy in adults. J Intensive Care 2015;3:15.

27. Pisani MA, Friese RS, Gehlbach BK, Schwab RJ, Weinhouse GL, Jones SF. Sleep in the intensive care unit. Am J Respir Crit Care Med 2015;191:731-8.

28. Corral J, Sánchez-Quiroga MÁ, Carmona-Bernal C, SánchezArmengol Á, de la Torre AS, Durán-Cantolla J, et al. Conventional polysomnography is not necessary for the management of most patients with suspected obstructive sleep apnea: noninferiority, randomized controlled trial. Am J Respir Crit Care Med 2017;196:1181-90. 
Supplementary Table 1. Clinical characteristics of patients enrolled and not enrolled during the study period

\begin{tabular}{lccc}
\hline Variable & Unenrolled patient $(n=52)$ & Enrolled patient $(n=13)$ & P-value \\
\hline Age $(\mathrm{yr})$ & $66(57-77)$ & $70(60-75)$ & 0.35 \\
Male sex & $28(54)$ & $10(77)$ & 0.13 \\
Body mass index $\left(\mathrm{kg} / \mathrm{m}^{2}\right)$ & $23.2(19.8-25.4)$ & $24.9(21.7-25.7)$ & 0.23 \\
APACHE II score & $23(17-30)$ & $25(20-35)$ & 0.37 \\
SOFA score & $9(5-13)$ & $9(5-12)$ & 0.99 \\
SAPS II & $50(34-70)$ & $54(39-66)$ & 0.79 \\
Reason for mechanical ventilation & & & 0.26 \\
$\quad$ Respiratory & $37(71)$ & $9(69)$ & \\
Cardiovascular & $13(25)$ & $2(15)$ & \\
$\quad$ Sepsis or septic shock & $2(4)$ & $2(15)$ & 0.17 \\
Duration of mechanical ventilation (day) & $3(2-6)$ & $5(3-7)$ & 0.27 \\
Length of ICU stay (day) & $6(3-10)$ & $8(6-10)$ & \\
\hline
\end{tabular}

Values are presented as median (interquartile range) or number (\%).

APACHE: Acute Physiology and Chronic Health Evaluation; SOFA: Sequential Organ Failure Assessment; SAPS: Simplified Acute Physiology Score; ICU: intensive care unit. 